INFORMACIÓN

$\square \square \square$ 



\section{Seminario Interuniversitario de Teoría de la Educación}

La XV edición del Seminario Interuniversitario de Teoría de la Educación se celebró en noviembre de 1996 en la Universidad de La Laguna.

Durante tres dias se sometieron a debate las nuevas perspectivas que en educación introducen las Tecnologías de la Información y la Comunicación. Cuatro ponencias y más de treinta comunicaciones vertebraron la reflexión sobre los cambios que introducen en la mentalidad individual y social, las posibilidades que ofrecen para la educación permanente, su aplicación en los procesos de aprendizaje y las limitaciones que se presentan para su integración eficaz en el proceso de enseñanza-aprendizaje.

El próximo Seminario será organizado por el Departamento de Educación de la Universidad de Navarra a finales de noviembre de 1997 y versará sobre la Profesionalización Docente. 